\title{
Stress urinary incontinence in pregnant women: a review of prevalence, pathophysiology, and treatment
}

\author{
Bussara Sangsawang • Nucharee Sangsawang
}

Received: 24 August 2012 / Accepted: 26 January 2013 / Published online: 23 February 2013

(C) The Author(s) 2013. This article is published with open access at Springerlink.com

\begin{abstract}
Introduction and hypothesis Stress urinary incontinence (SUI) is the most common type of urinary incontinence (UI) in pregnant women and is known to have detrimental effects on the quality of life in approximately $54.3 \%$. Pregnancy is the main risk factor for the development of SUI. This review provides details of the pathophysiology leading to SUI in pregnant women and SUI prevalence and treatment during pregnancy.

Methods We conducted a PubMed search for Englishlanguage and human-study articles registered from January 1990 to September 2012. This search was performed for articles dealing with prevalence and treatment of SUI during pregnancy. In the intervention studies, we included studies that used a randomized controlled trial (RCT) design or studies comparing a treatment intervention to no treatment. Results A total of 534 articles were identified; 174 full-text articles were reviewed, and 28 of them met eligibility criteria and are reported on here. The mean prevalence of SUI during pregnancy was $41 \%$ (18.6-60\%) and increased with gestational age. The increasing pressure of the growing uterus and fetal weight on pelvic-floor muscles (PFM) throughout pregnancy, together with pregnancy-related hormonal changes, may lead to reduced PFM strength as well as their supportive and sphincteric function. These cause mobility of the bladder neck and urethra, leading to urethral sphincter incompetence. Pelvic floor muscle exercise (PFME) is a safe and effective treatment for SUI during pregnancy, without significant adverse effects.
\end{abstract}

A related article can be found at doi:10.1007/s00192-012-2017-3.

B. Sangsawang $(\bowtie) \cdot$ N. Sangsawang

Department of Obstetrics and Gynecological Nursing, Faculty of

Nursing, Srinakharinwirot University, 215-216 Ammarinnivet III

Saimai Soi 79, Saimai Rd.,

Bangkok 10220, Thailand

e-mail: twinnui@hotmail.com
Conclusions Understanding these issues can be useful for health-care professionals when informing and counseling pregnant women to help prevent SUI during pregnancy and the postpartum period.

Keywords Stress urinary incontinence · Pregnancy ·

Prevalence $\cdot$ Pathophysiology $\cdot$ Treatment $\cdot$ Review article

\section{Introduction}

Stress urinary incontinence (SUI), the complaint of involuntary loss of urine on effort or physical exertion or sneezing or coughing [1], is the most common type of urinary incontinence (UI) in pregnant women. It is known to have detrimental effects on quality of life (QoL) in approximately $54.3 \%$ of all pregnant women in four domains: physical activity, travel, social relationships, and emotional health [2]. Pregnant women with UI have statistically significant lower QoL during pregnancy than those without UI [3], and the QoL of incontinent pregnant women worsens with increasing gestational age to term [4]. Pregnant women with urgency (UUI) or mixed (MUI) incontinence had worse QoL scores during pregnancy than those with SUI alone. QoL scores on the physical, social, and emotional functioning domains were low, whereas scores on mobility and embarrassment domains were higher, suggesting a minimal restriction in lifestyle [5]. According to van Brummen et al. [6], the bother of lower urinary tract symptoms (LUTS) occurred most frequently at 36 weeks of pregnancy and were still a bother at 1 year after pregnancy. Interestingly, SUI occurred in the older maternal age groups, and the presence of bothersome LUTS occurred at 12 weeks of pregnancy, both of which were accounted to the predictive factor of bothersome SUI at 1 year after delivery. According to that study, cesarean section seemed to have a protective effect on bothersome SUI at 1 year after delivery. 
Mascarenhas et al. [3] reported that UI negatively affects social relationships and particularly interferes with sexual relationships. Dolan et al. [2] found that UI impinges on sexual relationships. Although SUI severity increases with pregnancy progression from the first to the third trimester [7] and during 36 weeks of gestation, $16.9 \%$ of pregnant women report having moderate to greatly bothersome UUI [6]. However, the QoL of pregnant women was found to be mildly affected by UI [8]. This may be because UI symptoms were not severe [9]. Pregnant women tend to consider this to be a common discomfort associated with pregnancy and a consequence of childbirth in the postpartum period [10]. Van de Pol et al. [4] found significantly higher rates of depressive symptoms and SUI during pregnancy than after childbirth. Another important impact of pregnancy-related UI is an increased risk of permanent incontinence in the postpartum period or later in life [11, 12]. Many studies have reported that pregnant women who had UI during pregnancy are at higher risk for postpartum UI than those without UI during pregnancy [13-15].

Pregnancy and delivery-related factors are considered to be the main risk factors for SUI development during pregnancy. The purpose of this review is to explain the pathophysiology leading to SUI in pregnant women and SUI prevalence and treatment during pregnancy. This information can be useful for health-care professionals when informing and counseling pregnant women in SUI prevention during pregnancy and the postpartum period.

\section{Materials and methods}

This review was performed following the Preferred Reporting Items for Systematic Reviews and Meta-Analyses (PRISMA) guidelines [16]. We conducted a PubMed search for English-language and human-study articles registered from January 1990 to September 2012 using the following search terms: epidemiology, prevalence, urinary incontinence, stress urinary incontinence, pregnancy, pregnant women, pelvic-floor-muscle exercise, pelvic-floor-muscle training, and conservative treatment Conference proceedings and abstracts from the International Continence Society annual meetings were also searched. Additional relevant publications were selected from the reference lists of identified articles, and abstracts presented at international meeting were also included. No language restriction was defined. Abstracts and conventional reports were excluded. All articles were screened by title and abstract by BS and NS. Studies reporting on the prevalence of all UI that included SUI, UUI, and MUI in pregnant women both primigravidae and multigravidae were selected. Intervention studies related to pelvic-floor-muscle exercises (PFME), pelvic-floormuscle training (PFMT), and other conservative treatments to prevent and treat UI during pregnancy and the postnatal period were included. In intervention studies, we included studies that used a randomized controlled trial (RCT) design or that compared a treatment intervention to no treatment. Noncomparative studies (i.e., pre-post studies, case report, case series) were excluded. A total of 534 publications in PubMed were identified. Titles and abstracts were screened for relevance and applicability, and 360 articles were excluded. The remaining 174 articles were screened in full text. Of these, 26 articles were included: 18 of UI prevalence and eight of UI treatment during pregnancy and the postnatal period met eligibility criteria as defined in Fig. 1.

\section{The prevalence of urinary incontinence in pregnancy}

The most common type of UI in pregnant women is SUI. However, the true prevalence of SUI is still unknown. There are many studies on the prevalence of SUI during pregnancy, and results vary depending on study method and design, such as definitions of UI, evaluation questionnaire, and stage of pregnancy [12].

Most studies focused on European or Western counties. Only a few studies determined SUI during pregnancy in Asia, especially in Southeast Asia. Wesnes et al. [17] presented questionnaire data from the Norwegian Mother and Child Cohort Study at the Norwegian Institute of Public Health and found that the most common type of UI was SUI in high prevalence in both nulliparous and multiparous women, $31 \%$ and $42 \%$, respectively. Morkved and Bø [18]

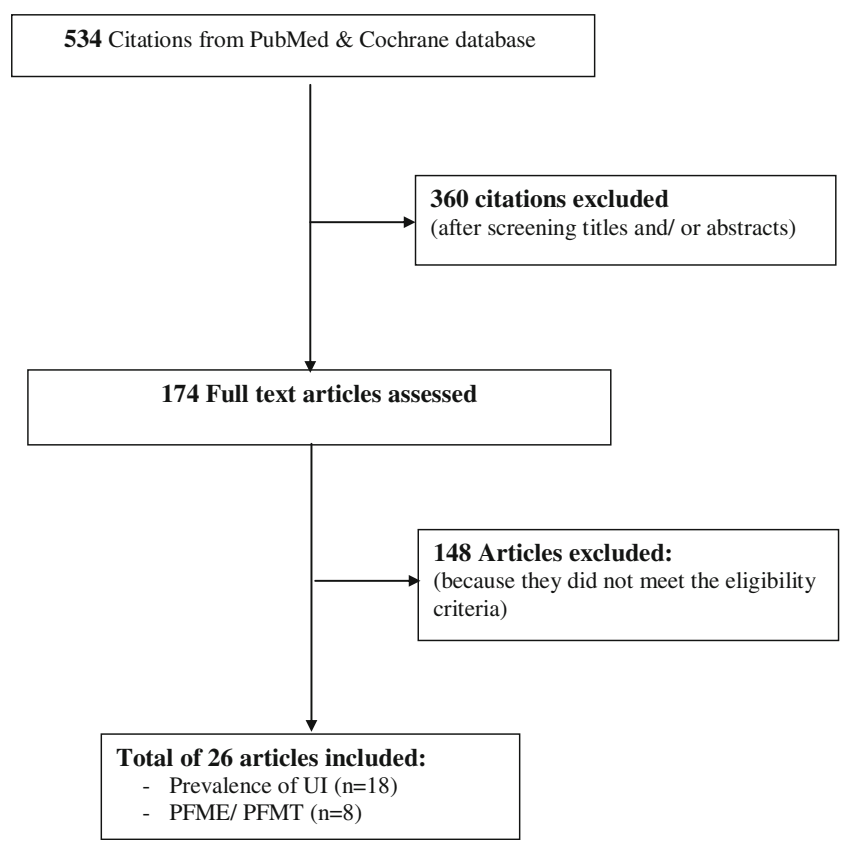

Fig. 1 Selection process for the review of stress urinary incontinence (SUI) prevalence and treatment during pregnancy 
from Norway found the prevalence of SUI during pregnancy was $42 \%$. According to the same study, SUI was $38 \%$ 8 weeks after delivery. Other studies from Europe (Table 1), UK [19], Spain [20], Scotland [21], Germany [22], and Denmark [23] found similarly high prevalence of SUI during pregnancy.

A large population survey conducted in China [24] found a little lower prevalence of UI compare with in Europe, but it was still high among the pregnancy population: $26.7 \%$ of pregnant women presented with UI, including $18.6 \%$ with SUI, $4.3 \%$ with MUI, and $2.0 \%$ with UUI. In Taiwan, there was some discrepancy. One study found a low incidence in primiparous women: a prevalence of SUI, MUI, and UUI of $26.7 \%, 6.1 \%$, and $4.7 \%$, respectively [25]. Another study found a high prevalence: SUI, $46.1 \%$ [26]. A study conducted in Jordan also found the prevalence of SUI as high as $45 \%$ and UUI at $35 \%$ [27]. In India, the prevalence of SUI, MUI, and UUI during pregnancy was $19.2 \%, 3.8 \%$, and $2.9 \%$, respectively [28]. The highest reported prevalence of SUI was in the USA. Thomason et al. [29] reported up to $60 \%$, whereas Raza-Khan et al. [30] found $70 \%$ and $75 \%$ of UI prevalence in nulliparous and multiparous women, respectively, and $32 \%$ pure SUI. A high prevalence was also reported South America [31]. Results reported from Australia were comparable with those in the USA: $64 \%$ of women reported incontinence during pregnancy [32]. The prevalence of SUI and MUI were more common during pregnancy than was UUI alone: $36.9 \%, 13.1 \%$, and $5.9 \%$, respectively [33]. In a multiethnic population in Norway, Bø et al. [34] conducted their investigation in the first trimester. They investigated the prevalence rate of SUI at 28 weeks of gestation> and found the lowest prevalence in women of African origin: $26 \%$. The prevalence in the Middle East population was $36 \%$, slightly higher than in women of African origin but lower than individual investigation. A prevalence of $40 \%$ and $43 \%$ was found in East and Southeast Asian women, which is higher than individual reports. The highest incidence was reported among women of European or North American origin: $45 \%$. Although the prevalence reported was different worldwide, the concordant feature was the increasing prevalence with gestational age $[25,26,35]$. The authors reported prevalence was highest in third trimester, followed by in the second and then first trimesters $[25,28,36]$. Only $13-19 \%$ was reported in the first trimester [25, 37]. The second trimester was comparable at $19.2 \%$, but a significantly higher prevalence was found in third trimester: $37.5 \%$ [25]. UI was higher with advance gestational age, as reported by Wijma et al. [36], who found the incidence of UI increased from $30 \%$ at 28-32 weeks of gestation to $35 \%$ at $36-38$ weeks of gestation, which is similar to that reported by Kerrebroeck et al. [38]. The number of pregnant women with SUI varied according to this summary, and the prevalence of SUI ranged from $18.6 \%$ to $60 \%$, UUI from $2 \%$ to $35 \%$, and MUI from $3.8 \%$ to $13.1 \%$, increasing with gestational age. Many studies of the prevalence of UI are shown in Table 1.

\section{Anatomy and physiology of the lower urinary tract during pregnancy}

Normal anatomy and physiology of the lower urinary tract plays an important role in the background of the knowledge of the continence mechanism. Thorough knowledge of the anatomy and physiology provides the concept of the UI. The normal anatomy, the pelvic floor musculature complex, and its normal physiology are beyond the scope of the review.

Pregnancy has significant effect on lower urinary tract function. In uncomplicated pregnancy, micturition frequency is influenced by the physiologic state of the bladder. Frequency has been described as diurnal changes, which may be up to seven times or more of normal, and slight nocturnal changes of one or more times during the night. The incidence is the same in both primigravidae and multigravidae women [39]. The first trimester is the most common time of onset. The uterine weight is the most important factor affecting frequency throughout the pregnancy. Uterine weight not only exerts pressure on the bladder but also irritates the bladder. Normal bladder capacity in the first trimester is $410 \mathrm{ml}$ [39]. In late pregnancy, descent of the presenting part of fetus has an additional effect on bladder irritation. Bladder capacity in the third trimester reduces to $272 \mathrm{ml}$ in conjunction with increased irritability of detrusor muscles [39]. Alternative causes include nervous and hormonal influences. Indeed, the onset of frequency in late pregnancy is a common symptom of engagement of the fetal head [39]. Approximately $80 \%$ of pregnant women, both primigravidae and multigravidae, experience increased micturition frequency at some time during pregnancy [39]. Increased frequency usually begins in early pregnancy but can occur in the later stage; it disappears in mid pregnancy, which may be due to the increase in bladder capacity to $460 \mathrm{ml}$ in the second trimester, and returns in the later weeks. [39]. Once increased frequency has occurred, it is nearly always progressive and becomes increasingly worse until term [39]. Increased frequency during pregnancy results in polyuria and is associated with increased fluid intake. However, which is the cause and which the effect remains an unsolved issue. Average daily excretion, output, and fluid intake are highest in the second trimester and lowest in the third [39].

Uterine position is another issue that plays a significant role. The impacted retrovert gravid uterus causes fluid retention because it interferes with the obliteration of the posterior urethrovesical angle. It does not elevate the urethrovesical junction in the pelvis, nor does it elongate the urethra [39]. 


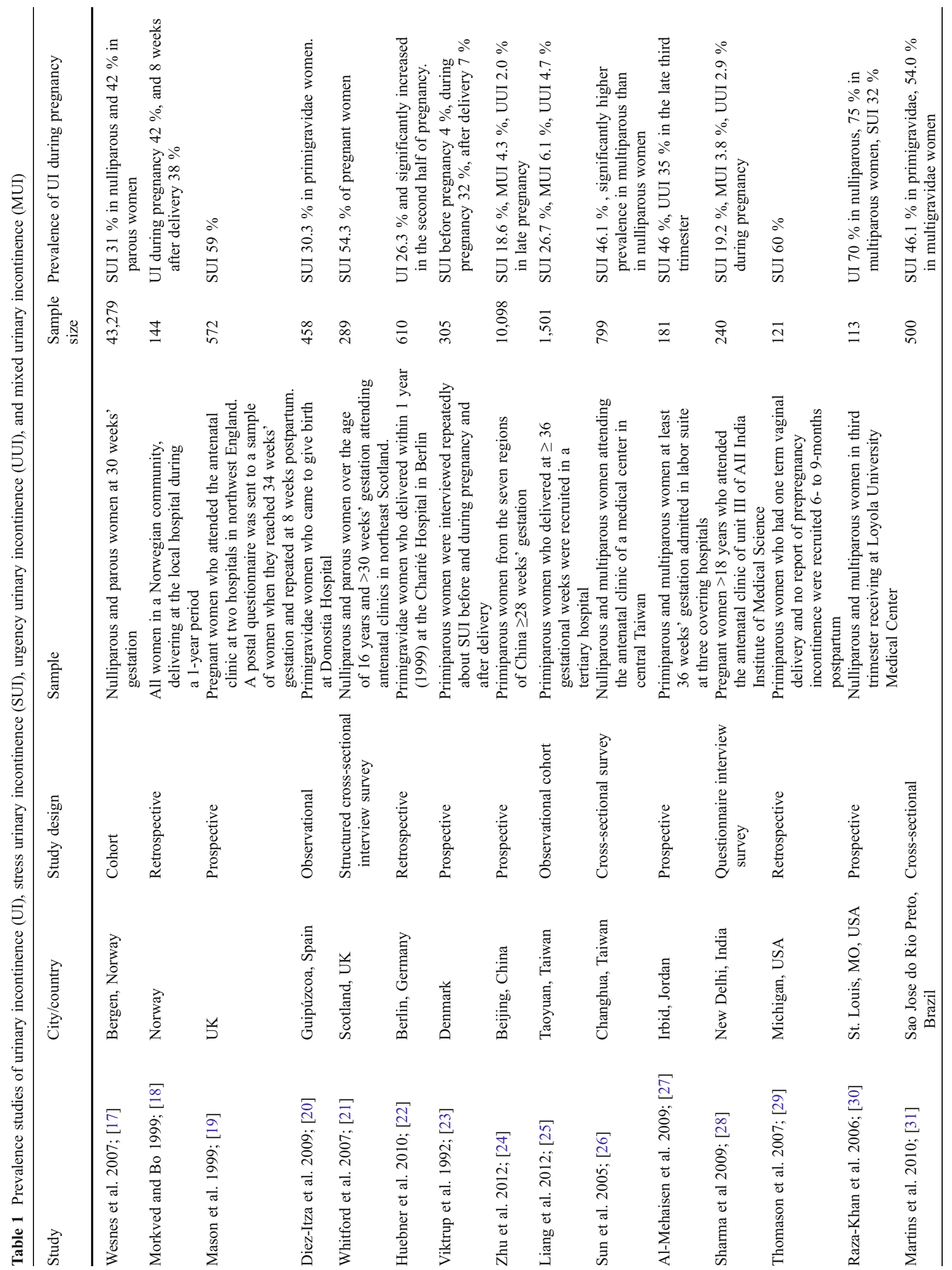




\section{Pathophysiology of stress urinary incontinence during pregnancy}

PFM weakness causes bladder-neck and urethral mobility, leading to urethral sphincter incompetence [40, 41]. When the pregnant woman coughs, sneezes, laughs, or moves, intra-abdominal pressure increases, and this pressure is transmitted to the bladder. When pressure inside the bladder is greater than urethral closure pressure, incorporated with weakness of the urethral sphincter, SUI is the result. Pregnancy is one of the main risk factors for the development of SUI in young women [42-44]. Studies in pregnant women with SUI have found significantly decreased PFM strength in incontinent pregnant women compared with continent pregnant women [45]. Furthermore, there is a significantly higher prevalence of SUI in pregnant women than in nonpregnant women [46-48]. Pregnancy may also be associated with reduced PFM strength, which can cause SUI. However, the exact causes of pregnancy-related SUI remain unclear [49]. Physiological changes during pregnancy may lead to reduced PFM strength and SUI development in pregnant women due to the following mechanism.

Trauma to the PFM due to maternal weight, the uterus, and the fetus

Physiological weight gain during pregnancy may lead to increased pressure on the PFM and bladder, which may result in greater urethral mobility [50, 51]. Furthermore, excess maternal weight gain may impair blood flow and innervations to the bladder and urethra [52]. Several studies show the association between obesity and SUI. Zhu et al. [24] reported that the risk of SUI increased with increasing prenatal BMI [odds ratio $(\mathrm{OR}=1.037)$ ]. Liang et al. [25] reported that women with a prepregnancy BMI $>30 \mathrm{~kg} / \mathrm{m}^{2}$ were at increased risk of developing SUI during pregnancy. Glazener et al. [53] found that women with UI first occurring during pregnancy had a BMI $>25 \mathrm{~kg} / \mathrm{m}^{2}$ [OR $1.68,95 \%$ confidence interval (CI) 1.12-2.43]. Increased maternal weight correlated with increased intra-abdominal pressure during urodynamic assessments [54, 55]. In addition, increased BMI was not only associated with UI but with pelvic organ prolapse (POP) as well. Gyhagen et al [56] found that symptomatic POP increased $3 \%$ with each unit increase of BMI (OR 1.03; $95 \%$ CI 1.01-1.05). They also found that women with POP more frequently had UI and UI> for $>10$ years compared with women without POP. Weakening of PFM is found more often in women with POP [57]. Obesity or high BMI before pregnancy is a potentially modifiable risk factor for SUI; weight reduction may be an effective treatment option [58]. Weight loss by behavioral change can significantly improve SUI [58].

The growing uterus and fetus weigh solely on PFM, which contributes to chronic stress on PFM throughout 
pregnancy and results in PFM weakness. Sphincter strength and its supportive function of PFM are jeopardized [41, 47, 59]. Furthermore, multigravidity causes a decrease in PFM strength at a rate of $22-35 \%$ beginning at a gestational age of 20 weeks and lasting until 6 weeks postpartum [40]. Hilde et al. [60], in a cross-sectional study of 300 nulliparous women at 18-22 weeks' gestational age showed that continent pregnant women had significantly higher PFM strength and endurance compared with incontinent pregnant women ( $p=0.003$ and $p=0.01$, respectively).

Prenatal issues and childbirth can damage the pudendal nerve, caudal aspects of the levator ani muscle, fascial pelvic organ supports, and the external and internal anal sphincters [61, 62]. This damage reduces PFM strength and may lead to increased bladder-neck and urethral mobility $[63,64]$ and cause mobility of the urethrovesical junction [11]. Wijma et al. [65] found increased bladder-neck mobility from early pregnancy onward to near term. Jundt et al. [66] found that pregnant women with SUI had more a mobile bladder neck than continent pregnant women.

\section{Collagen changes during pregnancy}

Collagen changes included both tensile properties and number. Changes in tensile properties contribute to reduced functional support of PFM, and reduced total collagen content may result in joint laxity and stretching of pelvic ligaments [67]. Several studies have reported a decrease in the total collagen content in women with SUI [63, 68]. Keane et al. [63] showed that nulliparous women with SUI had significantly less collagen content in their tissues than did continence pregnant women $(p<0.0001)$. They also concluded that the etiology of SUI in these pregnant women appears due to both quantitative and qualitative reduction in collagen.

Chen et al [69] showed the extracellular matrix (ECM) component is related to increased elastase activity in vaginal tissues obtained from SUI patients. In addition, the breakdown of collagen, smooth-muscle inhibition, and inflammatory processes play an important role in contributing to SUI. Lin et al. found the relevant genes that influence cellular signaling pathways, including matrix metalloproteinases (MMPs), regulator of G-protein signaling 2 (RGS2), and SMAD2 [70]. Skorupski et al. also found more expression of $1 \mathrm{G} / 2 \mathrm{G} M M P-1$ and the $5 \mathrm{~A} / 6 \mathrm{~A} M M P-3$ promoter single nucleotide polymorphisms (SNPs) in women with POP than in the population with a normal PFM [71]. Genetic and environmental factors contribute to the occurrence of SUI and POP. A study of twins by Altman et al [72] on SUI and POP analyzed 3,376 monozygotic and 5,067 dizygotic female twins and found a greater similarity in outcomes in monozygotic twins. In a study of nulliparous women, Dietz et al. [73] demonstrated the heritability of bladder-neck mobility. The systematic review by Lince et al. [74] found a substantially greater likelihood of SUI in family members with women with POP compares with women without POP, indicating that genetic predisposition play an important role in the development of POP.

\section{Hormonal changes during pregnancy}

Changes in relaxin and progesterone levels during pregnancy may have a significant role in the development of SUI [75].Relaxin, which plays an important role in maintaining urinary continence during pregnancy [76], could stimulate tissue growth in the lower urinary tract and increase urethral pressure. There is a marked increase in relaxin concentration to peak at a gestational age of 10-14 weeks and then decrease to a stable level of approximately half the peak value at the 17 th-24th week of pregnancy, resulting in decreased growth of the urethral epithelium [77, 78]. This may lead to a decrease in urethral pressure [67]. As pregnant women with SUI have lower urethral pressure than continent pregnant women [79], lower relaxin concentrations in late pregnancy, therefore, correlate with a higher prevalence of SUI at the second and third trimesters [76].

Progesterone increases during pregnancy from $24 \mathrm{ng} / \mathrm{ml}$ at the 8th week to $150 \mathrm{ng} / \mathrm{ml}$ at the 36th week [80]. Increased progesterone may relax smooth muscles in the urinary system [81], result in reduced ureter, bladder, and urethral tone [82]. Values urethral pressure profile parameters below the median value and defective transmission of pressure over the urethra were observed in almost all pregnant women who experienced SUI during pregnancy. These observations suggest that an inherent weakness of the urethral sphincter mechanism plays a key role in the pathogenesis of SUI [80]. However, alterations in hormone levels during pregnancy were not correlated with changes in urethral pressure profile measurements [80].

\section{The expansion of the uterus and fetal weight}

Two major factors - expansion of the uterus and increment increase in fetal weight with gestational age, especially at the third trimester-influence the incontinence mechanism. They put direct pressure on the bladder, which may lead to changing the bladder-neck position [66] and reducing bladder capacity, contributing to bladder pressure that exceeds urethral pressure $[65,83]$. This results in urine leakage.

In summary, commonly encountered prenatal physiological changes such as increasing pressure of the growing uterus and fetal weight on PFM throughout pregnancy, together with pregnancy-related hormonal changes in progesterone, estrogen, and relaxin, may lead to reduced strength and supportive and sphincteric function of PFM. PFM muscle weakness causes bladder-neck and urethral 
mobility, leading to urethral sphincter incompetence. Hence, when intra-abdominal pressure is increased with coughing, sneezing, laughing, or moving, the pressure inside the bladder becomes greater than the urethral closure pressure and the urethral sphincter is not strong enough to maintain urethral closure. Urinary leakage will be the result. In particular, SUI is common during pregnancy and puerperium. After delivery, SUI symptoms resolve in the vast majority of cases [84]. The healing process may take some time after the delivery [85], but in a significant percentage of women, it can persist in subsequent stages of life [84]. In primiparae women, SUI symptoms tend to resolve within 3 month after delivery [86].

The relevant literature reports that the prevalence of UI decreases in the postpartum period [85, 87]. In general, UI can affect $27.4 \%$ of parous women for 6 months postpartum, with only a small portion of women experiencing spontaneous resolution [88]. Thomason et al. [29] found that only $8 \%$ of pregnant women who developed UI during pregnancy had resolution, but in $47 \%$ of those who had UI, incontinence had not resolved at 6 months postpartum. Glazener et al. [53] found that $13.5 \%$ of primigravid women had SUI 3 months after delivery, whereas Wesnes et al. [55] showed an SUI rate around $14 \%$ at 6 months after delivery. Groutz et al. [89] found that 1 year after the first spontaneous vaginal delivery, $10.3 \%$ of women had SUI.

Despite this clear association, the mechanism involved in SUI remains unclear. Similarly, the pathophysiology of the development of SUI during pregnancy is not clearly understood. However, it has been suggested that it could be caused by both hormonal and mechanical changes that occur during this period $[90,91]$. After pregnancy, most women recover their prepregnancy hormonal levels, and pressure of the enlarged uterus on the bladder and PFM resolves. Postnatal remission of SUI may be explained by the resolution of hormonal and metabolic changes associated with pregnancy and spontaneous healing of traumatic lesions due to vaginal childbirth [92]. The compensation may be due to PFM, which play a urethral support role, and it may be aided by pelvic floor training [92]. Improvement in PFM strength in women during the postpartum period showed that pregnancy, with its hormonal and mechanic effects, is a very important risk factor for UI during pregnancy [87].

\section{Treatment for stress urinary incontinence during pregnancy}

During pregnancy and postpartum, conservative therapy or perineal rehabilitation by PFME is the first-line intervention to treat SUI [35]. Pregnant women are often instructed to perform PFME to prevent the development and treat symptoms of SUI during pregnancy [93]. Other treatments, whether medical or surgical, must not be proposed at as the first intervention during pregnancy or during the immediate postpartum period [35].

\section{Pelvic floor muscle exercise}

PFME, the repetitively selective voluntary contraction and relaxation of specific PFM [1], also known as Kegel exercises, are the most popular method of treatment for SUI. In the late 1940s, an American gynecologist named Arnold Kegel first introduced this method for treating postpartum UI and improving the function and tone of PFM following childbirth. PFME have been successful because postpartum women who have performed these exercises have reported cure rates as high as $84 \%$ and improvement rates as high as $100 \%$ [94]. PFME is the most commonly recommended conservative therapy for pregnant women with SUI. PFME under the direction of a therapist (re-educator or midwife) reduces the prevalence of UI in the short term compared with simple advice about individual PFME [35]. Many investigators have assessed the effectiveness of PFME, as shown in Table 2.

PFME is used to strengthen the pelvic floor and periurethral muscles to improve the continence mechanism [44, 87, 95]. As a result, this method can either cure or relieve SUI by reducing incontinence severity, including frequency and volume of urine leakage $[45,96]$. PFME prescribed during pregnancy improves pregnancy UI and reduces the prevalence of UI in late pregnancy and early postpartum $[35,97]$. Dinc et al. [87] found that pregnant women with PFME had a significant decrease in UI episodes during pregnancy and in the postpartum period. Undoubtedly, their PFM strength increased to a larger extent. Sangsawang and Serisathien [96] investigated the effects of a PFME on the severity of SUI in 66 pregnant women who had SUI at gestational ages of 20-30 weeks. After the PFME program, women in the experimental group had significantly reduced frequency, volume of urine leakage, and score of perceived SUI severity compared with those in the control group. They concluded that the 6-week PFME program was able to decrease symptom severity in pregnant women with SUI. Sampselle et al. [98] studied the effects of PFME on SUI and PFM strength during pregnancy and postpartum in 72 primigravid women with gestational ages of 20 weeks. This study suggested that PFME can reduce the incidence of SUI at gestational ages of 35 weeks and at 6 weeks and 6 months postpartum by significantly increasing PFM strength compared with women who did not perform PFME. Morkved et al. [99] found that pregnant women who performed PFME reported $32 \%$ UI at 36 weeks of gestational ages compared to $48 \%$ in the control group $(p=.007)$. The number of urinary leakage episodes at gestational age 36 weeks was also significantly lower in the experimental group $(p=.014)$. 


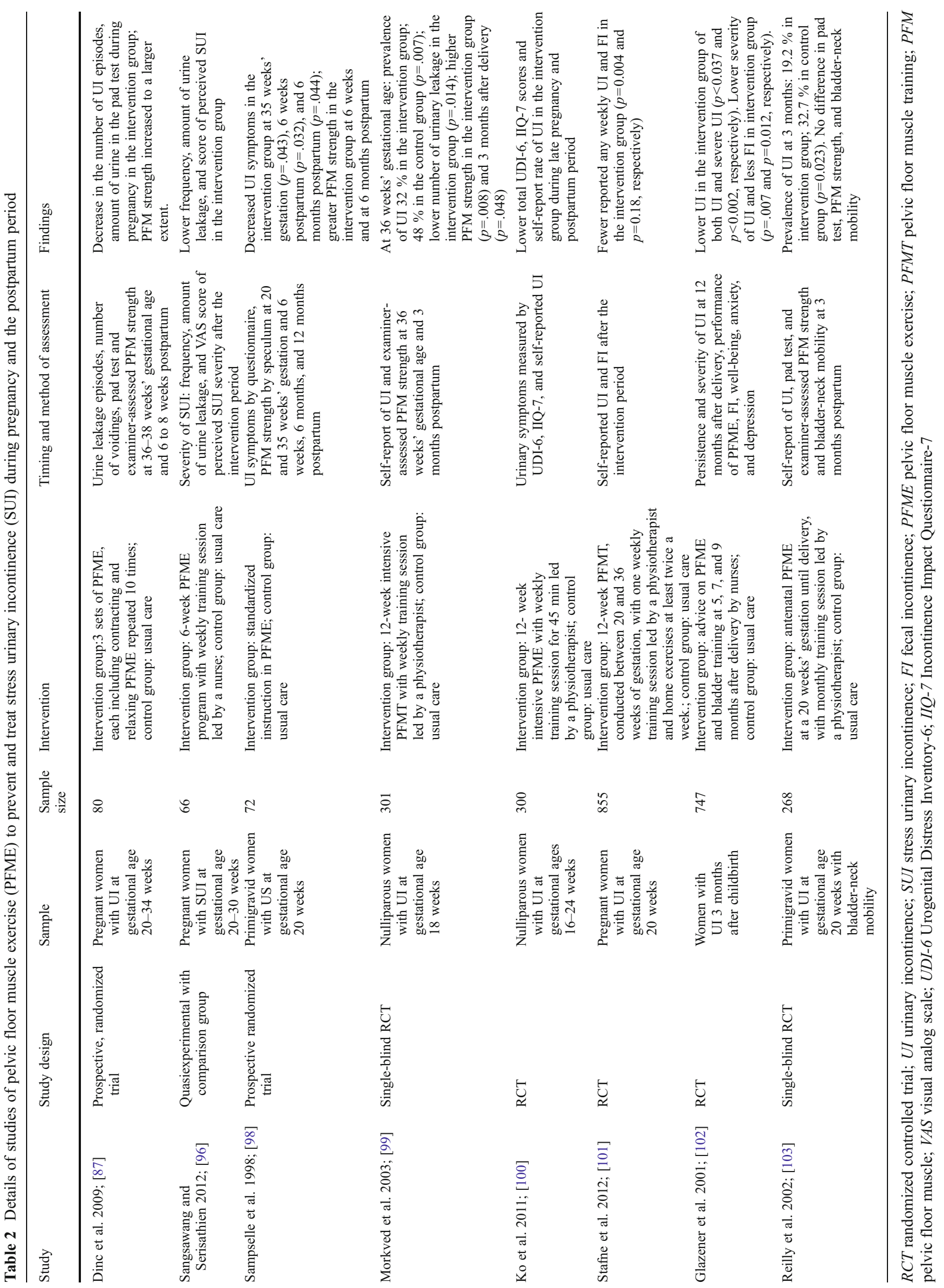


Furthermore, PFM strength was significantly higher in women with PFME at gestational age 36 weeks and 3 months after delivery than in the control group $(p=.008$ and $p=.048$, respectively). During late pregnancy and the postpartum period, Ko et al. [100] found that women in the PFME group had significantly lower total Urogenital Distress Inventory-6 (UDI-6) and Incontinence Impact Questionnaire-7 (IIQ-7) scores; their self-report rate of UI was also less than in the control group. This study concluded that PFME applied in pregnancy was effective in treating and preventing UI during pregnancy, and this effect may persist to postpartum period.

Stafne et al. [101] assessed the effect of a 12-week pelvic floor muscle training (PFMT) to reduce self-reported UI and fecal incontinence (FI) in late pregnancy in 855 women. After the intervention, the authors found that fewer women in the intervention group reported any weekly UI and FI (11\% vs. $19 \%, P=0.004$ and $3 \%$ vs. $5 \%, P=0.18$, respectively). They indicated that pregnant women who practice PFMT can prevent and treat UI in late pregnancy. Glazener et al. [102] studied the effects of PFME on the severity of UI at 12 months after delivery in 747 mothers who still had UI 3 months postpartum. They found that mothers in the intervention group had significantly less UI and severe UI than the control group (59.9\% vs $69.0 \%, p<$ 0.037 and $19.7 \%$ vs $31.8 \%, p<0.002$, respectively). FI was also less common in the intervention group than the control group ( $4.4 \%$ vs $10.5 \%, p=0.012)$. The authors concluded that PFMT provided by nurses seems to reduce UI and FI that persists for 12 months postpartum. Reilly et al. [103] studied the effects of antenatal PFME at a gestational age of 20 weeks until delivery for the prevention of postpartum SUI in 268 primigravid women with bladder-neck mobility. The authors suggested that antenatal PFME are effective in reducing the risk of postpartum SUI in primigravid women with bladder-neck mobility at 3 months postpartum. However, there were no changes in bladder-neck mobility and no difference in PFM strength between groups after exercise.

PFME is a specific exercise for PFM and is different from exercise of other muscles in the body. Thus, PFME requires a strong commitment from women. Moreover, this form of exercise requires dedication, endurance, and effort on the part of women in order to result in effective SUI treatment [104].

Women without symptoms of SUI may not want to invest their time in PFME [93]. Women with moderate to severe symptoms of SUI may achieve more improvement in their incontinence than women with mild symptoms. Alewijnse et al. [105] found that women with severe symptoms were more likely to maintain a higher adherence to PFME than women with mild to moderate symptoms. Burns et al. [106] argued that women with mild symptoms may not perceive their incontinence as a serious problem, whereas patients with severe symptoms recognized the incontinence as an ongoing problem and view adherence to exercise as positive training to affect a cure. Findings of that study are in accordance with the study of Sangsawang and Serisathien [96], who found that more than half $(54.3 \%)$ and nearly half $(45.7 \%)$ of pregnant women in the intervention group had severe and moderate symptoms of SUI, respectively, before participating in the program. Thus, pregnant women may have perceived their incontinence symptoms as a serious problem that could affect their QoL. After completing the program at the sixth week, $100 \%$ of pregnant women in the intervention group were able to perform PFME every day during participated in the program [96]. Women with SUI symptoms were encouraged to perform this exercise continually, resulting in alleviation of SUI symptoms and contributing to the continence mechanism. Morkved et al. [99] found that $19 \%$ of pregnant women had some noncompliance (i.e., skipping classes) in the training schedules of a 12-week antepartum PFME, which is a high rate compared with compliance in drug trials of similar duration. Goode et al. [107] found that $11 \%$ of women dropped out of the 8-week PFME class because the treatment required too much effort and time. In a 15-year follow-up, long-term adherence to PFME was found to be low, with no difference between intensive and home training programs [108].

In summary, PFME is the first-line conservative treatment for women with SUI before consideration of other treatments [97]. PFME is more a effective treatment for SUI during pregnancy because it is a safe treatment without complications, inexpensive, simple to perform, does not require instruments, and can be done anywhere and anytime [97, 109].

\section{Conclusions}

The most common type of UI in pregnant women is SUI. The number of pregnant women with SUI in our literature review was variable, with prevalence ranging from $18.6 \%$ to $75 \%$ [16-32, 34] and increasing with gestational age. The increasing pressure of the growing uterus and fetal weight on PFM throughout pregnancy, together with pregnancy-related hormonal changes, may lead to reduced strength of the supportive and sphincteric function of PFM. PFM weakness causes bladder-neck and urethral mobility, thus leading to urethral sphincter incompetence. Hence, when intra-abdominal pressure increases, pressure inside the bladder becomes greater than the urethral closure pressure, and the urethral sphincter is not strong enough to close the urethra, resulting in urine leakage. PFME is an effective treatment for SUI during pregnancy and has no significant adverse effects. Continence can be improved when incontinent pregnant women adequately perform PFME.

Acknowledgments The authors thank Dr. Denchai Laiwattana, M.D., for valuable critique of the manuscript.

Conflicts of interest None. 
Open Access This article is distributed under the terms of the Creative Commons Attribution License which permits any use, distribution, and reproduction in any medium, provided the original author(s) and the source are credited.

\section{References}

1. Haylen BT, de Ridder D, Freeman RM et al (2010) An International Urogynecological Association (IUGA)/International Continence Society (ICS) joint report on the terminology for female pelvic floor dysfunction. Int Urogynecol J 21(1):5-26

2. Dolan LM, Walsh D, Hamilton S, Marshall K, Thompson K, Ashe RG (2004) A study of quality of life in primigravidae with urinary incontinence. Int Urogynecol J Pelvic Floor Dysfunct 15:160-164

3. Mascarenhas T, Coelho R, Oliveira M, Patricio B (2003) Impact of urinary incontinence on quality of life during pregnancy and after childbirth. Paper presented at the 33th annual meeting of the International Continence Society, Florence, Italy, October 9, 2003

4. van de Pol GG, Van Brummen HJ, Bruinse HW, Heintz AP, van der Vaart CH (2007) Is there an association between depressive and urinary symptoms during and after pregnancy? Int Urogynecol J Pelvic Floor Dysfunct 18:1409-1415

5. van Brummen HJ, Bruinse HW, Van de Pol G, Heintz AP, Van der Vaart CH (2006) What is the effect of overactive bladder symptoms on woman's quality of life during and after first pregnancy? BJU Int 97(2):296-300

6. van Brummen HJ, Bruinse HW, van de Pol G, Heintz AP, van der Vaart CH (2006) Bothersome lower urinary tract symptoms 1 year after first delivery: prevalence and the effect of childbirth. BJU Int 98(1):89-95

7. Milsom I, Altman D, Lapitan MC, Nelson R, Sillén U, Thom D (2009) Epidemiology of urinary (UI) and faecal (FI) incontinence and pelvic organ prolapse (POP). In: Abrams P, Cardozo L, Khoury S, Wein A (eds) Incontinence: 4th International Consultation on Incontinence. Health Publication Ltd, Paris, pp 35-112

8. Kocaöz S, Talas MS, Atabekoğlu CS (2010) Urinary incontinence in pregnant women and their quality of life. J Clin Nurs 19(23-24):3314-3323

9. Adaji SE, Shittu OS, Bature SB, Nasir S, Olatunji O (2010) Suffering in silence: pregnant women's experience of urinary incontinence in Zaria, Nigeria. Eur J Obstet Gynecol Reprod Biol 150(1):19-23

10. Marecki M, Seo JY (2010) Perinatal urinary and fecal incontinence: suffering in silence. J Perinat Neonatal Nurs 24(4):330-340

11. King JK, Freeman RM (1998) Is antenatal bladder neck mobility a risk factor for postpartum stress urinary incontinence? Br J Obstet Gynaecol 105:1300-1307

12. Schytt E, Lindmark G, Waldenstrom U (2004) Symptoms of stress incontinence 1 year after childbirth: prevalence and predictors in a national Swedish sample. Acta Obstet Gynecol Scand 83:928-936

13. Burgio KL, Zyczynski H, Locher JL, Richter HE, Redden DT, Wright KC (2003) Urinary incontinence in the 12-month postpartum period. Obstet Gynecol 102:1291-1298

14. Hvidman L, Foldspang A, Mommsen S, Nielsen JB (2003) Postpartum urinary incontinence. Acta Obstet Gynecol Scand 82:556-563

15. Liang CC, Wu MP, Lin SJ, Lin YJ, Chang SD, Wang HH (2013) Clinical impact of and contributing factors to urinary incontinence in women 5 years after first delivery. Int Urogynecol J 24(1):99-104

16. Moher D, Liberati A, Tetzlaff J, Altman DG (2009) Preferred reporting items for systematic reviews and meta-analyses: the PRISMA statement. BMJ 21;339:b2535
17. Wesnes SL, Rortveit G, Bø K, Hunskaar S (2007) Urinary incontinence during pregnancy. Obstet Gynecol 109(4):922-928

18. Mørkved S, Bø K (1999) Prevalence of urinary incontinence during pregnancy and postpartum. Int Urogynecol J Pelvic Floor Dysfunct 10:394-398

19. Mason L, Glenn S, Walton I, Appletion C (1999) The prevalence of stress incontinence during pregnancy and following delivery. Midwifery 15(2):120-128

20. Diez-Itza I, Ibañez L, Arrue M, Paredes J, Murgiondo A, Sarasqueta C (2009) Influence of maternal weight on the new onset of stress urinary incontinence in pregnant women. Int Urogynecol J Pelvic Floor Dysfunct 20(10):1259-1263

21. Whitford HM, Alder B, Jones M (2007) A cross-sectional study of knowledge and practice of pelvic floor exercises during pregnancy and associated symptoms of stress urinary incontinence in North-East Scotland. Midwifery 23(2):204-217

22. Huebner M, Antolic A, Tunn R (2010) The impact of pregnancy and vaginal delivery on urinary incontinence. Int $\mathrm{J}$ Gynecol Obstet 110(3):249-251

23. Viktrup L, Lose G, Rolff M, Barford K (1992) The symptom of stress incontinence caused by pregnancy or delivery in primiparas. Obstet Gynecol 79:945-949

24. Zhu L, Li L, Lang JH, Xu T (2012) Prevalence and risk factors for peri- and postpartum urinary incontinence in primiparous women in China: a prospective longitudinal study. Int Urogynecol J 23(5):563-572

25. Liang CC, Chang SD, Lin SJ, Lin YJ (2012) Lower urinary tract symptoms in primiparous women before and during pregnancy. Arch Gynecol Obstet 285(5):1205-1210

26. Sun MJ, Chen GD, Chang SY, Lin KC, Chen SY (2005) Prevalence of lower urinary tract symptoms during pregnancy in Taiwan. J Formos Med Assoc 104(3):185-189

27. Al-Mehaisen LM, Al-Kuran O, Lataifeh IM et al (2009) Prevalence and frequency of severity of urinary incontinence symptoms in late pregnancy: a prospective study in the north of Jordan. Arch Gynecol Obstet 279(4):499-503

28. Sharma JB, Aggarwal S, Singhal S, Kumar S, Roy KK (2008) Prevalence of urinary incontinence and other urological problems during pregnancy: a questionnaire based study. Arch Gynecol Obstet 279(6):845-851

29. Thomason AD, Miller JM, Delancey JO (2007) Urinary incontinence symptoms during and after pregnancy in continent and incontinent primiparas. Int Urogynecol J Pelvic Floor Dysfunct 18(2):147-151

30. Raza-Khan F, Graziano S, Kenton K, Shott S, Brubaker L (2006) Peripartum urinary incontinence in a racially diverse obstetrical population. Int Urogynecol J Pelvic Floor Dysfunct 17(5):525-530

31. Martins G, Soler ZA, Cordeiro JA, Amaro JL, Moore KN (2010) Prevalence and risk factors for urinary incontinence in healthy pregnant Brazilian women. Int Urogynecol J 21(10):1271-1277

32. Chiarelli P, Campbell E (1997) Incontinence during pregnancy. Prevalence and opportunities for continence promotion. Aust N Z J Obstet Gynaecol 37(1):66-73

33. Brown SJ, Donath S, MacArthur C, McDonald EA, Krastev AH (2010) Urinary incontinence in nulliparous women before and during pregnancy: prevalence, incidence, and associated risk factors. Int Urogynecol J 21(2):193-202

34. Bø K, Pauck Øglund G, Sletner L, Mørkrid K, Jenum A (2012) The prevalence of urinary incontinence in pregnancy among a multi-ethnic population resident in Norway. Br J Obstet Gynaecol 119(11):1354-1360

35. Fritel X, Fauconnier A, Bader G et al (2010) Diagnosis and management of adult female stress urinary incontinence: guidelines for clinical practice from the French College of Gynaecologists and Obstetricians. Eur J Obstet Gynecol Reprod Biol 151(1):14-19 
36. Wijma J, Weis Potters AE, Tinga DJ, Aarnoudse JG (2008) The diagnostic strength of the 24-h pad test for self-reported symptoms of urinary incontinence in pregnancy and after childbirth. Int Urogynecol J Pelvic Floor Dysfunct 19(4):525-530

37. Thorp JM, Norton PA, Wall LL, Kuller JA, Eucker B, Wells E (1999) Urinary incontinence in pregnancy and the puerperium: a prospective study. Am J Obstet Gynecol 181:266-273

38. van Kerrebroeck P, Abrams P, Chaikin D et al (2002) The standardisation of terminology in nocturia: report from the Standardisation Sub-committee of the International Continence Society. Neurourol Urodyn 21(2):179-183

39. Francis WJ (1960) Disturbances of bladder function in relation to pregnancy. J Obstet Gynaecol Br Emp 67:353-366

40. Davis K, Kumar D (2003) Pelvic floor dysfunction: a conceptual framework for collaborative patient-centred care. J Adv Nurs 43(6):555-568

41. Morkved S, Bo K, Schei B, Salvesen KA (2003) Pelvic floor muscle training during pregnancy to prevent urinary incontinence: a singleblind randomized controlled trial. Obstet Gynecol 101(2):313-319

42. FitzGerald MP, Graziano S (2007) Anatomic and functional changes of the lower urinary tract during pregnancy. Urol Clin N Am 34(1):7-12

43. McKinnie V, Swift SE, Wang W et al (2005) The effect of pregnancy and mode of delivery on the prevalence of urinary and fecal incontinence. Am J Obstet Gynecol 193(2):512-518

44. Joanna Briggs Institute (2011) The Joanna Briggs Institute best practice information sheet: the effectiveness of pelvic floor muscle exercises on urinary incontinence in women following childbirth. Nurs Health Sci 13(3):378-381

45. Morkved S, Salvesen KA, Bo K, Eik-Nes S (2004) Pelvic floor muscle strength and thickness in continent and incontinent nulliparous pregnant women. Int Urogynecol J Pelvic Floor Dysfunct 15:384-390

46. Hojberg KE, Salvig JD, Winslow NA, Lose G, Secher NJ (1999) Urinary incontinence: prevalence and risk factors at 16 weeks of gestation. Br J Obstet Gynecol 106:842-850

47. MacLennan AH, Taylor AW, Wilson DH, Wilson D (2000) The prevalence of pelvic floor disorder and their relationship to gender, age, parity and mode of delivery. Br J Obstet Gynecol 107:1460-1470

48. Peyrat L, Haillot O, Bruyere F, Boutin JM, Bertrand P, Lanson Y (2002) Prevalence and risk factors of urinary incontinence in young and middle-aged women. Br J Urol 89:61-66

49. Viktrup L (2002) The risk of urinary tract symptom five years after the first delivery. Neurourol Urodyn 21(1):2-29

50. Pregazzi R, Sartore A, Troiano L et al (2002) Postpartum Urinary symptoms: prevalence and risk factors. Obstet Gynecol 103(2):179-182

51. Greer WJ, Richter HE, Bartolucci AA, Burgio KL (2008) Obesity and pelvic floor disorders: a systematic review. Obstet Gynecol 112(2 Pt 1):341-349

52. Bump RC, Sugerman H, Fantl JA, McClish DM (1992) Obesity and lower urinary tract function in women: effect of surgically induced weight loss. Am J Obstet Gynecol 166:392-399

53. Glazener CM, Herbison GP, MacArthur C et al (2006) New postnatal urinary incontinence: obstetric and other risk factors in primiparae. Br J Obstet Gynaecol 113(2):208-217

54. Van Kessel K, Reed S, Newton K, Meier A, Lentz G (2011) The second stage of labor and stress urinary incontinence. Am J Obstet Gynecol 184(7):1571-1575

55. Wesnes SL, Hunskaar S, Bo K, Rortveit G (2009) The effect of urinary incontinence status during pregnancy and delivery mode on incontinence postpartum. A cohort study. Br J Obstet Gynaecol 116(5):700-707

56. Gyhagen M, Bullarbo M, Nielsen T, Milsom I (2013) Prevalence and risk factors for pelvic organ prolapse 20 years after childbirth: a national cohort study in singleton primiparae after vaginal or caesarean delivery. Br J Obstet Gynaecol 120(2):152-160

57. Singh K, Jakab M, Reid WM, Berger LA, Hoyte L (2003) Threedimensional magnetic resonance imaging assessment of levator ani morphologic features in different grades of prolapse. Am J Obstet Gynecol 188:910-915

58. Stothers L, Friedman B (2011) Risk factors for the development of stress urinary incontinence in women. Curr Urol Rep 12(5):363-369

59. Wijma J, Weis Potters AE, van der Mark TW, Tinga DJ, Aarnoudse JG (2007) Displacement and recovery of the vesical neck position during pregnancy and after childbirth. Neurourol Urodyn 26(3):372-376

60. Hilde G, Stær-Jensen J, Ellström Engh M, Brækken IH, Bø K (2012) Continence and pelvic floor status in nulliparous women at midterm pregnancy. Int Urogynecol J 23(9):1257-1263

61. Dietz HP, Wilson PD (2005) Childbirth and pelvic floor trauma. Best Pract Res Clin Obstet Gynaecol 19(6):913-924

62. Dietz HP, Schierlitz L (2005) Pelvic floor trauma in childbirthmyth or reality? Aust N Z J Obstet Gynaecol 45(1):3-11

63. Keane DP, Sims TJ, Abrams P, Bailey AJ (1997) Analysis of collagen status in premenopausal nulliparous women with genuine stress incontinence. Br J Obstet Gynaecol 104(9):994-998

64. Dietz HP, Eldridge A, Grace M, Clarke B (2004) Does pregnancy affect pelvic organ mobility? Aust N Z J Obstet Gynaecol 44:517-520

65. Wijma J, Weis Potters AE, de Wolf BTHM, Tinga DJ, Aarnoudse JG (2001) Anatomical and functional changes in the lower urinary tract during pregnancy. Br J Obstet Gynaecol 108:726-732

66. Jundt K, Scheer I, Schiessl B, Karl K, Friese K, Peschers UM (2010) Incontinence, bladder neck mobility, and sphincter ruptures in primiparous women. Eur J Med Res 15(6):246-252

67. Chaliha C, Kalia V, Stanton SL, Monga A, Sultan AH (1999) Antenatal prediction of postpartum urinary and fecal incontinence. Obstet Gynecol 94:689-694

68. Falconer C, Ekman G, Malmstrom A, Ulmsten U (1994) Decreased collagen synthesis in stress-incontinence women. Obstet Gynecol 84:583-586

69. Chen B, Wen Y, Yu X, Polan ML (2007) The role of neutrophil elastase in elastin metabolism of pelvic tissues from women with stress urinary incontinence. Neurourol Urodyn 26(2):274-279

70. Lin G, Shindel AW, Banie L et al (2009) Molecular mechanisms related to parturition-induced stress urinary incontinence. Eur Urol 55(5):1213-1222

71. Skorupski P, Jankiewicz K, Miotła P et al (2012) The polymorphisms of the MMP-1 and the MMP-3 genes and the risk of pelvic organ prolapse. Int Urogynecol J. doi:10.1007/s00192-012-1970-1

72. Altman D, Forsman M, Falconer C, Lichtenstein P (2008) Genetic influence on stress urinary incontinence and pelvic organ prolapse. Eur Urol 54(4):918-922

73. Dietz HP, Hansell NK, Grace ME, Eldridge AM, Clarke B, Martin NG (2005) Bladder neck mobility is a heritable trait. $\mathrm{Br}$ J Obstet Gynaecol 112(3):334-339

74. Lince SL, van Kempen LC, Vierhout ME, Kluivers KB (2012) A systematic review of clinical studies on hereditary factors in pelvic organ prolapse. Int Urogynecol J 23(10):1327-1336

75. Hilton P, Dolan LM (2004) Pathophysiology of urinary incontinence and pelvic organ prolapse. Br J Obstet Gynaecol 111(sup.1):5-9

76. Kristiansson P, Samuelsson E, Schoultz B, Svardsudd K (2001) Reproductive hormones and stress urinary incontinence in pregnancy. Acta Obstet Gynecol Scand 80:1125-1130

77. Kristiansson P, Svardsudd K, Schoultz B (1996) Serum relaxin, symphyseal pain, and back pain during pregnancy. Am J Obstet Gynecol 175:1342-1347

78. Harvey MA, Johnston SL, Davies GA (2008) Mid-trimester serum relaxin concentrations and post-partum pelvic floor dysfunction. Acta Obstet Gynecol Scand 87(12):1315-1321 
79. Chaliha C, Stanton SL (2002) Urological problems in pregnancy. Br J Urol 89:469-476

80. van Geelen JM, Lemmens WA, Eskes TK, Martin CB Jr (1982) The urethral pressure profile in pregnancy and after delivery in healthy nulliparous women. Am J Obstet Gynecol 144(6):636-649

81. Swift SE, Ostergard DR (1993) Effects of progesterone on the urinary tract. Int Urogynecol J 4(4):232-236

82. Tincello DG, Teare J, Fraser WD (2003) Second trimester concentration of relaxin and pregnancy related incontinence. Eur J Obstet Gynecol Reprod Biol 106:237-238

83. Chaliha C, Bland JM, Monga A, Stanton SL, Sultan AH (2000) Pregnancy and derivery: a urodynamic viewpoint. Br J Obstet Gynaecol 107:1354-1359

84. Viktrup L, Rortveit G, Lose G (2006) Risk of stress urinary incontinence twelve years after the first pregnancy and delivery. Obstet Gynecol 108(2):248-254

85. Thom DH, Rortveit G (2010) Prevalence of postpartum urinary incontinence: a systematic review. Acta Obstet Gynecol Scand 89(12):1511-1522

86. Viktrup L, Lose G, Rolf M, Barfoed K (1993) The frequency of urinary symptoms during pregnancy and puerperium in the primipara. Int Urogynecol J 4(1):27-30

87. Dinc A, Kizilkaya Beji N, Yalcin O (2009) Effect of pelvic floor muscle exercises in the treatment of urinary incontinence during pregnancy and the postpartum period. Int Urogynecol J Pelvic Floor Dysfunct 20(10):1223-1231

88. Serati M, Salvatore S, Khullar V et al (2008) Prospective study to assess risk factors for pelvic floor dysfunction after delivery. Acta Obstet Gynecol Scand 87(3):313-318

89. Groutz A, Rimon E, Peled S et al (2004) Cesarean section: does it really prevent the development of postpartum stress urinary incontinence? A prospective study of 363 women one year after their first delivery. Neurourol Urodyn 23(1):2-6

90. Arrue M, Ibañez L, Paredes J et al (2010) Stress urinary incontinence six months after first vaginal delivery. Eur J Obstet Gynecol Reprod Biol 150(2):210-214

91. Hvidman L, Foldspang A, Mommsen S, Bugge Nielsen J (2002) Correlates of urinary incontinence in pregnancy. Int Urogynecol J Pelvic Floor Dysfunct 13(5):278-283

92. Fritel X, Ringa V, Quiboeuf E, Fauconnier A (2012) Female urinary incontinence, from pregnancy to menopause: a review of epidemiological and pathophysiological findings. Acta Obstet Gynecol Scand 91(8):901-910

93. Brostrøm S, Lose G (2008) Pelvic floor muscle training in the prevention and treatment of urinary incontinence in womenwhat is the evidence? Acta Obstet Gynecol Scand 87(4):384-402

94. Kegel N (1948) Progressive resistance exercise in the functional retroration of the perineal muscle. Am J Obstet Gynaecol 56:238-248

95. Hay-Smith J, Herbison P, Mørkved S (2002) Physical therapies for prevention of urinary and faecal incontinence in adults. Cochrane Database Syst Rev (2):CD003191
96. Sangsawang B, Serisathien Y (2012) Effect of pelvic floor muscle exercise programme on stress urinary incontinence among pregnant women. J Adv Nurs 68(9):1997-2007

97. Price N, Dawood R, Jackson SR (2010) Pelvic floor exercise for urinary incontinence: a systematic literature review. Maturitas 67(4):309-315

98. Sampselle CM, Miller JM, Mims BL, Delancey JOL, AshtonMiller JA, Antonakos CL (1998) Effect of pelvic muscle exercise on transient incontinence during pregnancy and after birth. Obstet Gynecol 91(3):406-412

99. Morkved S, Bo K, Schei B, Salvesen KA (2003) Pelvic floor muscle training during pregnancy to prevent urinary incontinence: a single-blind randomized controlled trial. Obstet Gynecol 101(2):313-319

100. Ko PC, Liang CC, Chang SD, Lee JT, Chao AS, Cheng PJ (2011) A randomized controlled trial of antenatal pelvic floor exercises to prevent and treat urinary incontinence. Int Urogynecol $\mathrm{J}$ 22(1):17-22

101. Stafne S, Salvesen K, Romundstad P, Torjusen I, Mørkved S (2012) Does regular exercise including pelvic floor muscle training prevent urinary and anal incontinence during pregnancy? A randomised controlled trial. Br J Obstet Gynaecol 119(10):1270-1280

102. Glazener CM, Herbison GP, Wilson PD et al (2001) Conservative management of persistent postnatal urinary and faecal incontinence: randomised controlled trial. BMJ 323(7313):593-596

103. Reilly ET, Freeman RM, Waterfield MR, Waterfield AE, Steggles P, Pedlar F (2002) Prevention of postpartum stress incontinence in primigravidae with increased bladder neck mobility: a randomised controlled trial of antenatal pelvic floor exercises. $\mathrm{Br} \mathrm{J}$ Obstet Gynaecol 109(1):68-76

104. Newman DK (2001) Conservative management of urinary incontinence in women. Prim Care Updat Obstet Gynecol $8(4): 153-162$

105. Alewijnse D, Mesters I, Metsemakers J, van den Borne B (2003) Predictors of long-term adherence to pelvic floor muscle exercise therapy among women with urinary incontinence. Heal Educ Res 18(5):511-524

106. Burns PA, Pranikoff K, Nochajski TH, Hadley EC, Levy KJ, Ory MG (1993) A comparison of effectiveness of biofeedback and pelvic muscle exercise treatment of stress incontinence in older community-dwelling women. J Gerontol 48:167-174

107. Goode PS, Burgio KL, Locher JL et al (2003) Effect of behavioral training with or without pelvic floor electrical stimulation on stress incontinence in women: a randomized controlled trial. JAMA 290(3):345-352

108. Bø K, Kvarstein B, Nygaard I (2005) Lower urinary tract symptoms and pelvic floor muscle exercise adherence after 15 years. Obstet Gynecol 105(5 Pt 1):999-1005

109. Allahdin S, Kambhampati L (2012) Stress urinary incontinence in continent primigravidas. J Obstet Gynaecol 32(1):2-5 